\title{
Nephrolithiasis as a presenting feature of chronic sarcoidosis
}

\author{
G Rizzato, P Fraioli, L Montemurro
}

\begin{abstract}
Background - Renal calculi have been reported to occur in about $10 \%$ of patients with chronic sarcoidosis, but nephrolithiasis as a presentation of this disease has not been studied.
\end{abstract}

Methods - The charts of 618 patients with histologically proven sarcoidosis, seen in the period October 1978-1992, were reviewed in order to identify nephrolithiasis at presentation.

Results - Seventeen patients had renal calculi which preceded other manifestations of sarcoidosis. In six the occurrence of calculi suggested the diagnosis. Another eight patients had a previous history of recurrent colic with calculi. The time intervals between the first calculus and the appearance of other manifestations of sarcoidosis ranged from one to 25 years, but it was over four years in only two cases and all had at least one calculus in the year before the diagnosis was made. In the other three patients appearance of the calculus was distant in time and was probably unrelated to their sarcoidosis. In most cases the sarcoidosis was chronic and needed long term treatment with corticosteroids. Four patients had further calculi during follow up (one month to 16 years) due to an improper withdrawal of treatment decided by the patient in two cases, and to the reduction in the corticosteroid dose in the other two.

Conclusions - Calculi were the presenting feature of sarcoidosis in six (1\%) patients, and were the first manifestation of the disease in a total of $14(2 \cdot 2 \%)$. This frequency is over 20 times the likely incidence of calculi in the general population. Renal calculi may therefore be a rare primary manifestation of sarcoidosis. In such cases the disease is likely to be chronic and to require long term corticosteroid therapy. Sarcoidosis should always be suspected in cases of nephrolithiasis of unknown origin. (Thorax 1995;50:555-559)

Sarcoid Clinic Medical Division Vergani, Niguarda Hospital, Milan, Italy

G Rizzato

P Fraioli

L Montemurro

Keywords: sarcoidosis, nephrolithiasis, hypercalciuria, hypercalcaemia, renal calculi.

Abnormal calcium metabolism is a well known feature of sarcoidosis. In 1954 Henneman et $a l^{1}$ were the first to suggest that the hypercalcaemic/hypercalciuric disturbance was related to endogenous overproduction of vitamin D. Their theory was supported by data on intestinal calcium hyperabsorption, and by historical evidence ${ }^{2}$ that showed exacerbations of hypercalcaemia or hypercalciuria during the summer when the skin is exposed to more ultraviolet light. More recently it was recognised that serum levels of 1,25-dihydroxyvitamin $\mathrm{D}_{3}$ were raised in some patients with sarcoidosis with hypercalciuria and/or hypercalcaemia. $^{34}$ An extrarenal overproduction of vitamin $\mathrm{D}$ was first reported in a hypercalcaemic, anephric male patient with sarcoidosis in $1981 .^{5}$ The source of this overproduction was found to be in the pulmonary macrophages of patients with acute sarcoidosis. ${ }^{6}$ It is suggested that excess vitamin $\mathrm{D}$ may result in increased intestinal calcium absorption and consequent hypercalcaemia, hypercalciuria, and renal calculi.

In studies in which hypercalcaemia is defined as a blood calcium level above $11 \mathrm{mg} / \mathrm{dl}$ $\left(0.11 \mathrm{~kg} / \mathrm{m}^{3}\right)$ in more than 50 patients the proportion with hypercalcaemia ranged from $3 \cdot 8 \%$ to $35.4 \%{ }^{7}$ In 243 patients studied in Philadelphia whose records were surveyed retrospectively, however, it was only $2.9 \%,{ }^{7}$ and of 137 patients studied prospectively only two had levels above $11 \mathrm{mg} / \mathrm{dl}$ which persisted, although nine others had isolated measurements at this level. ${ }^{7}$

Hypercalciuria is found more frequently; when defined as an excretion of more than $200 \mathrm{mg}$ daily on an intake of $400 \mathrm{mg}$ it occurred in $36(62 \%)$ of 58 patients with sarcoidosis and in $7.5 \%$ of normal subjects. ${ }^{8}$ Taking an upper limit of urinary calcium excretion rate of $300 \mathrm{mg} / 24$ hours, it was found in $77(40 \%)$ of 192 patients in London. ${ }^{9}$ Using urinary excretion rates of $>300 \mathrm{mg} /$ day in men or $>250 \mathrm{mg} /$ day in women, about $2-5 \%$ of healthy adults exhibit hypercalciuria. ${ }^{10}$

Renal calculi have been found in about $10 \%$ of patients with chronic sarcoidosis in three studies ${ }^{11-13}$ with a prevalence ranging from $1 \cdot 3-3 \%{ }^{14} 15$ to $14 \%^{8}$ in others. Curiously, despite a high frequency of renal calculi during follow up, the possibility of sarcoidosis presenting with nephrolithiasis has never been evaluated.

We present here a retrospective analysis of our patients with sarcoidosis, with the aim of defining the frequency of presentation with renal calculi, and the incidence of calculi during follow up.

\section{Methods}

Six hundred and eighteen patients with histologically proven sarcoidosis, seen between October 1978 and October 1992, were studied. The charts of all these patients were reviewed. 
Those who had a history of renal calculi before the appearance of sarcoidosis were included in the study and are the basis of the present report. In all these patients the other more common causes of hypercalciuria and/or renal calculi were excluded. None had evidence of hyperuricaemia or gout.

Patients with a history of renal colic, but without evidence of passing a calculus or demonstration of a calculus by urography or ultrasound, have been excluded. Likewise, patients whose asymptomatic calculi were disclosed at the first examination (due to pyuria or microscopic haematuria in most cases) are not included because our aim was to study patients in which the calculus was the first manifestation of the disease.

We have noted whenever possible: (1) the composition of the renal calculi, (2) biochemical data, (3) the time interval between the onset of renal colic and the appearance of other manifestations of sarcoidosis, (4) treatment given and why, (5) evolution of the chest radiograph, (6) chronicity, (7) appearance of further calculi after diagnosis and treatment with corticosteroids, (8) the occurrence of hydronephrosis and surgery (included lithotripsy), and (9) the relationship between sarcoidosis and renal calculi in any single case.

\section{Results}

In agreement with the above criteria we excluded 11 patients where renal colic without calculi preceded the diagnosis of sarcoidosis and 9 patients with a pulmonary presentation where calculi were observed at the first examination. In most of them microscopic haematuria or pyuria led to the detection of asymptomatic renal calculi.

Seventeen of the 618 patients $(2 \cdot 75 \%)$ had renal calculi before the appearance of systemic signs of sarcoidosis. As a first step in our study we considered whether the calculi could be ascribed to sarcoidosis. In three patients the relation between sarcoidosis and renal calculi appeared doubtful because of a long time in- terval (10 to 14 years, asymptomatic in two of the three) between the passage of a calculus and the evidence of sarcoidosis. One patient had Löfgren's syndrome and two had pulmonary mottling.

The other 14 patients $(2 \cdot 2 \%$ of 618$)$ are described in tables 1 and 2 . There were seven men and seven women with a mean (SD) age at the time of the first calculus of $43.6(14.8)$ years. Table 1 describes six patients where investigation of the cause of renal calculi led $\bar{O}$ to the diagnosis of unsuspected sarcoidosis. Table 2 describes eight other patients where $\stackrel{\mathbb{Q}}{\complement}$ the interval between the first renal calculus and the diagnosis of sarcoidosis ranged from one $\vec{\circ}$ to 25 years (being over four years in only two of them). In all these patients with a long $\vec{\omega}$ interval, recurrent colic and renal calculi had occurred before the diagnosis of sarcoidosis, and all had at least one calculus in the preceding year. Sarcoidosis, when discovered, had fea- $G$ tures suggesting longstanding unrecognised of disease. For example, patient no 12 in table 2 은 who lived in a small village in southern Italy, $70 \mathrm{~km}$ from the nearest hospital, had a history of recurrent renal colic with many calculi over 25 years. As a result of increasing dyspnoea, $\vec{\bullet}$ stage III sarcoidosis was discovered involving, on in addition, her liver and multiple lymph nodes. A chest radiograph had never previously been performed.

Most of the 14 patients had some pulmonary impairment as well as some extrapulmonary $\stackrel{\mathbb{Q}}{\Omega}$ manifestations, as shown in the tables. Between $\overrightarrow{\hat{O}}$ two and 20 determinations of urinary calcium levels were available in each patient, but in some we could not find a determination at the time of the first calculus. Most patients had hypercalciuria which recurred even during therapy, usually following a reduction in the corticosteroid dose. Hypercalciuria is recorded in 3 tables 1 and 2 when at least two determinations $\delta$ were over $300 \mathrm{mg} / 24$ hours before beginning treatment. One patient (patient 2 in table 1) 윽 had a history of hypercalcaemia (up to $16 \mathrm{mg} / \triangle$ dl) before reaching our clinic. He was treated elsewhere with calcitonin before his sarcoidosis

Table 1 Clinical data of patients presenting with renal calculi

\begin{tabular}{|c|c|c|c|c|c|c|c|c|c|c|}
\hline $\begin{array}{l}\text { Patient } \\
\text { no. }\end{array}$ & Sex & $\begin{array}{l}\text { Age } \\
\text { at 1st } \\
\text { stone }\end{array}$ & $\begin{array}{l}\text { Interval between 1st } \\
\text { stone and diagnosis }\end{array}$ & Stage* & $\begin{array}{l}\text { Other extrapulmonary } \\
\text { manifestationst }\end{array}$ & Biopsy & $\begin{array}{l}\text { Steroid } \\
\text { therapy }\end{array}$ & $\begin{array}{l}\text { Follow } \\
\text { up after } \\
\text { diagnosis }\end{array}$ & Chronic & $\begin{array}{l}\text { Further calculi } \\
\text { during follow } \\
\text { up }\end{array}$ \\
\hline $\begin{array}{l}1 \\
2\end{array}$ & $\begin{array}{l}\mathbf{F} \\
\mathbf{M}\end{array}$ & $\begin{array}{l}24 \\
27\end{array}$ & $\begin{array}{l}15 \text { days } \\
6 \text { months } \ddagger\end{array}$ & $\begin{array}{l}\text { II } \\
\text { III }\end{array}$ & $\begin{array}{l}\text { Cervical and groin lymph } \\
\text { nodes } \\
\text { Weight loss ( } 10 \mathrm{~kg} \text { ) } \\
\text { Hypercalcaemia (up to } \\
16 \mathrm{mg} / \mathrm{dl}) \ddagger \\
\text { Hypercalciuria (up to } \\
676 \mathrm{mg} / 24 \mathrm{~h} \text { ) }\end{array}$ & $\begin{array}{l}\text { Open lung } \\
\text { Daniel's }\end{array}$ & $\begin{array}{l}\text { Long term } \\
\text { Long term }\end{array}$ & $\begin{array}{l}6 \text { years } \\
3 \text { years }\end{array}$ & $\begin{array}{l}\text { Yes } \\
\text { Yes }\end{array}$ & $\begin{array}{l}\text { No } \\
\text { No }\end{array}$ \\
\hline 3 & F & 54 & 3 months & II & Cervical lymph nodes & $\begin{array}{l}\text { Peripheral lymph } \\
\text { node }\end{array}$ & No & 7 months & $?$ & No \\
\hline 4 & $\mathbf{M}$ & 40 & 15 days & II & $\begin{array}{l}\text { Arthralgias, skin lesions } \\
\text { Hypercalciuria (up to } \\
462 \mathrm{mg} / 24 \mathrm{~h} \text { ) }\end{array}$ & Mediastinoscopy & Long term & 2 years & Yes & No \\
\hline 5 & $\mathbf{M}$ & 39 & 1 month & III & $\begin{array}{l}\text { Skin lesions } \\
\text { Hypercalciuria (up to } \\
525 \mathrm{mg} / 24 \mathrm{~h} \text { ) } \\
1-25(\mathrm{OH})_{2} \mathrm{D}_{3}=56 \mathrm{pg} / \mathrm{ml}\end{array}$ & Skin & Long term & 6 years & Yes & No \\
\hline 6 & $\mathbf{M}$ & 43 & 10 days $\uparrow$ & I & $\begin{array}{l}\text { Cervical and groin lymph } \\
\text { nodes } \\
\text { Hoarseness }\end{array}$ & Vocal cord & Long term & 5 years & Yes & No \\
\hline
\end{tabular}

* According to chest radiography at time of diagnosis of sarcoidosis (no stage changes during follow up). 
Table 2 Clinical data of patients in whom renal calculi preceded the systemic manifestations of sarcoidosis

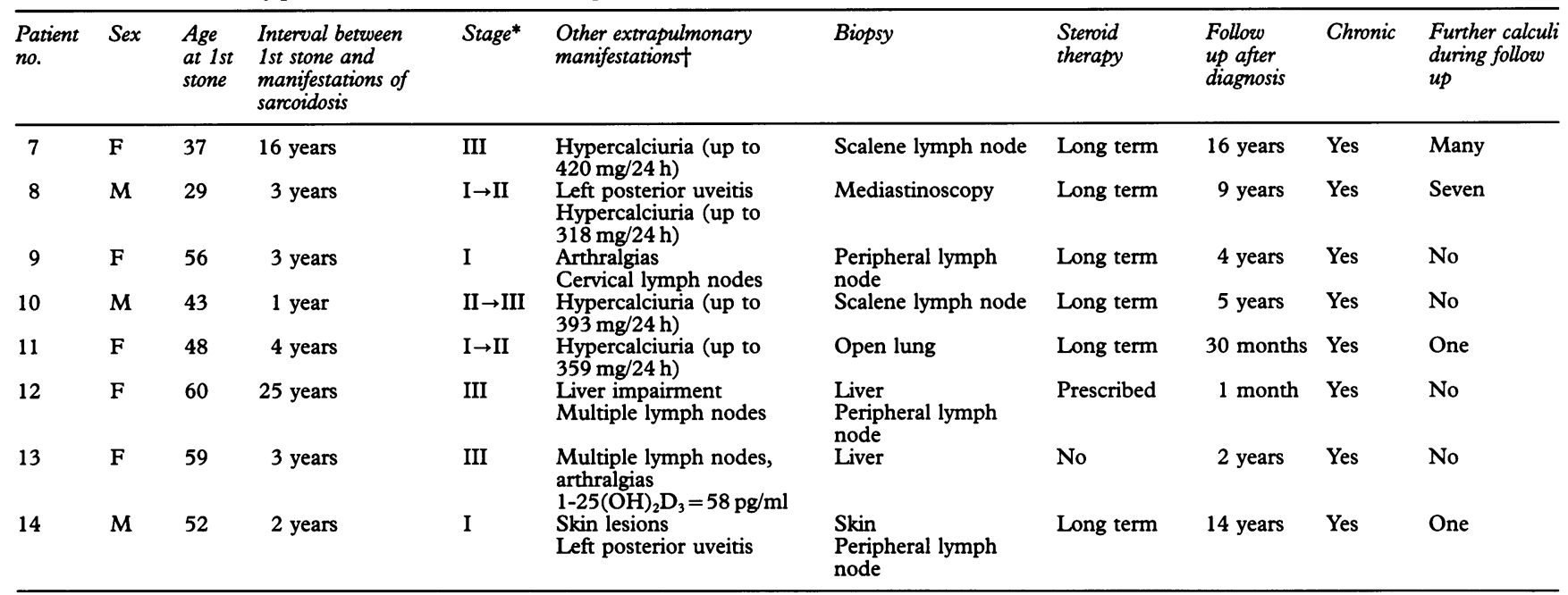

* According to chest radiography at the time of diagnosis of sarcoidosis (and changes during follow up).

+ At the time of diagnosis (or before).

was diagnosed. Measurements of serum levels of $1,25(\mathrm{OH})_{2} \mathrm{D}_{3}$ were available before treatment in four of the 14 patients, being normal in two, and high in two. Blood urea nitrogen and creatinine were normal in all patients. Chemical analysis of the calculi was available in only four patients before the diagnosis of sarcoidosis, and all were of calcium oxalate.

In most cases the sarcoidosis was chronic, lasting more than two years after the diagnosis of pulmonary disease. Only patient no 3 in table 1 and no 12 in table 2 had a short follow up (seven and one months, respectively). In three patients the chest radiograph remained at stage I over several years.

All but two patients needed long term corticosteroid therapy. This prevented further colic in 10 patients but four experienced recurrent renal colic and calculi, probably because in two cases (nos 11 and 14 in table 2) they stopped their steroids, and in the other two because of a re-emerging hypercalciuria with other signs of sarcoid activity following an attempt to reduce the steroid dose.

Hydronephrosis was present in five patients and three patients required surgery. Patient no 7 in table 2 required pyelotomy and ureterotomy in 1982 and lithotripsy in 1988; patients nos 8 and 9 underwent successful lithotripsy. Intrarenal calcifications were not seen.

Most patients are still being followed up and are on corticosteroid therapy.

\section{Discussion}

RENAL CALCULI IN THE GENERAL POPULATION In the general population the incidence and prevalence rates of nephrolithiasis are very variable, both geographically and between different ages and sexes. Moreover, there is considerable variation between studies with differing protocols.

Incidence, defined as the rate of new calculi formed in individuals with no previous calculi during a specific period, ${ }^{16}$ is unknown in Italy. In Rochester, Minnesota, a 25 year study showed that the annual incidence of renal cal- culi was stable over the study period for women at 36.0 per 100000 population and for men the incidence increased in 25 years from 78.5 to 123.6 per $100000 .{ }^{17}$ Three years later the rate of occurrence of calculi in the urinary tract was studied in a large population of over 139000 generally well adult members served by the Northern California Kaiser Foundation health plan. ${ }^{18}$ One hundred and twenty two per 100000 persons per year (180 men and 59 women) had an initial diagnosis of a new or recurrent calculus of the upper urinary tract. Urolithiasis was rare under the age of 20 , increased through ages 40-49 years for men (390/ $100000)$ and 50-59 years for women (149/ 100000 ), and then decreased in older subjects. In a more recent Japanese study the annual incidence of urolithiasis in a general population has been described as increasing from 46/ 100000 in 1965 to $68 / 100000$ in $1985 .{ }^{19}$ Incidence figures may be higher or lower than these when a particular population is selected. In a recent study limited to men over 40 years and including a population of 45000 participants from seven different regions of the USA, the incidence rate (calculi $/ 10^{5}$ person years) ranged from 273 in the Lower Midwest to 326 in New England. ${ }^{16}$ These rates are high, probably because they reflect an older population. Meria et $a l^{20}$ found a lower incidence $(66 / 100000)$ in pregnant women.

Prevalence figures are also higher if a study is carried out with radiology, thereby including asymptomatic people who may not have had a previous history of calculi. In a study from Glasgow by $\mathrm{Scott}^{21}$ radiographs were taken of 3398 subjects at random; possible calcified upper tract calculi were then further investigated, revealing a prevalence rate of $3.5 \%$. In Glostrup, Denmark, Emamian et al ${ }^{22}$ performed a similarly designed sonographic study on 665 normal adult volunteers, obtaining a $2 \cdot 1 \%$ prevalence. The difference between these results may be due to the fact that renal calculi smaller than $5 \mathrm{~mm}$ cannot easily be demonstrated by ultrasound.

In a prevalence study in Italy Borghi et $a l^{23}$ 
surveyed by questionnaire 2404 random individuals ( $1 \%$ of the entire Parma population) and found that $6 \cdot 1 \%$ had had at least one calculus during their life. Similarly, Curhan et $a l,{ }^{16}$ in a questionnaire study of 45000 men aged $40-75$ in seven different regions of the USA, found prevalence figures of between $6.6 \%$ and $9 \cdot 2 \%$. Similarly, in Uppsala, Sweden, Ljunghall and Hedstrand ${ }^{24}$ found a $13 \cdot 7 \%$ prevalence in 2322 men aged between 49 and 50 years, probably reflecting a bias in the particular population studied.

\section{RENAL CALCULI IN SARCOIDOSIS}

In 1988 Foster $^{25}$ described eight patients where systemic manifestations of biopsy proven sarcoidosis developed nine months to four years (average $2 \cdot 2$ years) after uveitis. He concluded that uveitis might be the presenting manifestation of sarcoidosis. His period of observation of 293 patients with uveitis of unknown origin was four years, and this is the reason why he could not describe a longer time interval between uveitis and the appearance of other manifestations of sarcoidosis. This study suggested that there might be other hitherto unexpected presenting manifestations of sarcoidosis.

One of these may be nephrolithiasis. Sarcoidosis is known to be accompanied by changes in the calcium metabolism. In Italy about $10 \%$ of patients develop renal calculi sooner or later during follow up of chronic disease. ${ }^{13}$ This figure is about twice the prevalence given by Borghi et $a l^{23}$ for a general population in an Italian town.

Sarcoidosis may be asymptomatic in some patients and renal calculi may therefore be the first manifestation of the disease. With this in mind we have shown that six patients had a renal calculus as the presenting feature which alerted the clinician to the diagnosis of sarcoidosis, while eight other patients had a probable sarcoidosis-related nephrolithiasis before the appearance of other manifestations. The combined incidence of $2 \cdot 2 \%$ should not be confused with the prevalence of calculi during follow up in patients with recognised sarcoidosis, reported in $10 \%$ of those patients. ${ }^{13}$ All our patients had at least one calculus in the year preceding the diagnosis. This incidence of $2 \cdot 2 \%$ (or 2200 per 100000 ) exceeds by more than 20 times the expected yearly rate of renal calculi in the general population (36 per 100000 in women and 123 in men in Rochester, ${ }^{17} 122$ in California, ${ }^{18}$ and 68 in KyotoOsaka $\left.{ }^{19}\right)$. We think that, in most of our cases, nephrolithiasis was the first manifestation of sarcoidosis. In a review of the literature we have found no previous cases described as presenting with renal calculi.

Why are calculi 20 times more frequent than in the general population at presentation, but only double during long term follow up? Probably because active sarcoidosis is treated in most cases, thereby reducing the risk of hypercalciuria and calculus formation, and also because the activity of sarcoidosis may decline gradually in most cases of chronic disease. In our study only two of 14 patients developed further calculi after diagnosis and proper treatment.

The lack of intrarenal calcifications on radiography is not surprising. This occurs rarely in sarcoidosis and only in patients with hypercalcaemia $^{26}$ or established renal failure. ${ }^{27}$ Moreover, this is found in renal biopsy samples or at necropsy more often than by radiographs. Löfgren et $a l^{28}$ carried out biochemical studies and renal biopsy in 16 patients with pulmonary sarcoidosis, six with hypercalcaemia over $12 \mathrm{mg} / \mathrm{dl}$ and 10 with lower serum calcium levels. Biopsy samples showed calcareous bodies only in five of the six patients with hypercalcaemia. Romer ${ }^{29}$ found nephrocalcinosis on renal biopsy in only five of 16 patients with hypercalcaemia; in four it was found also by simultaneous radiography. In our patients nephrocalcinosis was perhaps less likely because only one of them had a severe hypercalcaemia and none had renal failure.

Another interesting feature is that most of $\mathrm{O}$ our patients had chronic disease and needed $\vec{\longrightarrow}$ long term corticosteroid treatment. In the whole group of 618 patients, as well as in many other series, no more than $30 \%$ are chronic $\mathscr{E}$ and no more than $30 \%$ need corticosteroid treatment. Lupus pernio and bone cysts are recognised markers of the chronicity of sarcoidosis ${ }^{3031}$ and we suggest that renal calculi $\bar{\partial}$ at presentation may also be a marker of chronicity.

We conclude that renal calculi may be an unusual presentation of sarcoidosis. In such cases the disease is likely to be chronically active and long term corticosteroid treatment is probably required. A diagnosis of sarcoidosis should always be considered when patients present with renal calculi.

This study was supported by a grant (no. 629/93) from Regione Lombardia.

1 Henneman P, Dempsey E, Carroll E, Albright F. The cause of hypercalciuria in sarcoid and its treatment with cortisone and sodium phytate. $\mathcal{f}$ Clin Invest 1956;35:1229-42.

2 Taylor R, Lynch H, Wysor W. Seasonal influence of sunlight on the hypercalcemia of sarcoidosis. Am $\mathcal{F}$ Med 1963;34: N
221-7.

3 Papapoulos S. Clemens T, Fraher L, Lewin I, Sandler L, N O'Riordan J. 1,25-dihydroxycholecalciferol in the pathogenesis of the hypercalcemia of sarcoidosis. Lancet 1979; i: $627-30$.

4 Bell N, Stern P, Pantzer E, Sinha T, DeLuca F. Evidence $\underset{<}{0}$ that increased circulating $1_{a}, 25$-dihydroxyvitamin $\mathrm{D}$ is 0 the probable cause for abnormal calcium metabolism in sarcoidosis. F Clin Invest 1979;64:218-25.

5 Barbour G, Coburn J, Slatapolsky E, Norman A, Horst R. ? Hypercalcemia in an anephric patient with sarcoidosis: evidence for extrarenal generation of 1,25-dihydroxyvitamin D. N Engl f Med 1981;305:440-3.

6 Adams J, Gacad M, Singer F, Sharma O. Production of 1,25dihydroxyvitamin D3 by pulmonary alveolar macrophages $\mathbb{Q}$ from patients with sarcoidosis. In: Johns C, ed. Tenth International Conference on Sarcoidosis and Other GraAnn NY Acad Sci 1986;465: 587-94.

7 Goldstein R, Israel H, Becker K, Moore C. The infrequency of hypercalcemia in sarcoidosis. Am $\mathcal{F}$ Med 1971;51:21-9.

8 Lebacq E, Desmet G, Verhaegen H. Renal involvement in sarcoidosis. Postgrad Med $\mathcal{F}$ 1970;46:526-9.

9 James DG, Jones Williams W. Calcium levels. In: James DG, Jones Williams W, eds. Sarcoidosis and other granulomatous disorders. Philadelphia: Saunders, 1985:163-6.

10 Hodgkinson A, Pyrah L. The urinary excretion of calcium and inorganic phosphate in 344 patients with calcium and inorganic phosphate in 344 patients with

11 Muther $\mathrm{R}$, McCarron D, Bennett W. Renal manifestations of sarcoidosis. Arch Intern Med 1981;141:643-5.

12 Kenouch S, Mary JP. Sarcoidosis. In: Cameron S, Davison AM, Grunfeld JP, Kerr D, Ritz E, eds. Oxford textbook of clinical nephrology. Oxford: Oxford University Press, 1992: 576-82. 
13 Rizzato G. Sarcoidosis in Italy. Sarcoidosis 1992;9(Suppl 1): 145-7.

14 Longcope W, Frieman D. A study of sarcoidosis. Medicine (Baltimore) 1952;31:1-132.

15 Murphy G, Schirmer H. Nephrocalcinosis, urolithiasis and renal insufficiency in sarcoidosis. $\mathcal{F}$ Urol 1961;86:702-6.

16 Curham G, Rimm E, Willett W, Stamper M. Regional variation in nephrolithiasis incidence and prevalence among United States men. F Urol 1994;151:838-41.

17 Johnson C, Wilson D, O'Fallon W, Malek R, Kurland L Renal stone epidemiology: a 25-year study in Rochester, Minnesota. Kidney Int 1979;16:624-31.

18 Hiatt R, Dales L, Friedman G, Hunkeler E. Frequency of urolithiasis in a prepaid medical care program. $A m \mathcal{F}$ Erolithiasis in a prepaid miol 1982;115:255-65.

19 Yoshida O, Okada Y. Epidemiology of urolithiasis in Japan: a chronological and geographical study. Urol Int 1990;45: 104-11.

20 Meria P, Anidjar M, Hermieu J, Boccon-Jibod L. Urinary lithiasis and pregnancy. Prog Urol 1993;3:937-43.

21 Scott R. Prevalence of calcified upper urinary tract stone disease in a random population survey. $\mathrm{Br} F \mathrm{frol} 1987$; 59:111-7.

22 Emamian S, Nielsen M, Pedersen J, Ytte L. Sonographic evaluation of renal appearance in 665 adult volunteers. Acta Radiol 1993;34:482-5.
23 Borghi L, Ferretti P, Elia G, Amato F, Melloni E, Trapassi M, Novarini A. Epidemiological study of urinary tract stones in a Northern Italian city. Br f Urol 1990;65:231-5.

24 Ljunghall S, Hedstrand H. Epidemiology of renal stones in a middle-aged male population. Acta Med Scand 1975; 197:439-45.

25 Foster S. Ocular manifestations of sarcoidosis preceding systemic manifestations. In: Grassi C, Rizzato G, Pozzi $\mathrm{E}$, eds. Sarcoidosis and other granulomatous disorders. Amsterdam: Elsevier, 1988:177-81.

26 Hoffbrand B. The kidney in sarcoidosis. In: James DG, ed Sarcoidosis and other granulomatous disorders. New York: Marcel Dekker, 1994:335-43.

27 Coburn JW, Barbour GL. Vitamin D intoxication and sarcoidosis. In: Coe FL, ed. Hypercalciuric states. Pathogenesis, consequences, and treatment. Orlando: Grune \& Stratton, consequences, and

28 Löfgren S, Snellman B, Lindgren A. Renal complications in sarcoidosis: functional and biopsy studies. Acta Med Scand 1957;159:295-305.

29 Romer F. Renal manifestations and abnormal calcium metabolism in sarcoidosis. $Q f$ Med 1980;195:233-47.

30 James DG. Lupus pernio. Lupus 1992;1:129-31.

31 James DG. Bone. In: James DG, Jones Williams W, eds. Sarcoidosis and other granulomatous disorders. Philadelphia: Saunders, 1985:134-41. 